\title{
Design and Experimental Study of Pressure Compensation System for Full-Ocean-Depth Gas- Tight Sediment Sampler
}

\section{GuangPing Liu}

Hunan University of Science and Technology

Yongping Jin ( $\square$ jinyongping@hnust.edu.cn )

Hunan University of Science and Technology

\section{You-duo Peng}

Hunan University of Science and Technology

\section{Bu-yan Wan}

Hunan University of Science and Technology

\section{Original Article}

Keywords: Full-ocean-depth gas-tight sampler, Pressure-retaining, Pressure compensator, Gas tightness

Posted Date: February 15th, 2021

DOl: https://doi.org/10.21203/rs.3.rs-192497/v1

License: (c) This work is licensed under a Creative Commons Attribution 4.0 International License. Read Full License

Version of Record: A version of this preprint was published at Chinese Journal of Mechanical Engineering on April 1st, 2022. See the published version at https://doi.org/10.1186/s10033-022-00687-3. 
Title page

\section{Design and experimental study of pressure compensation system for full-ocean-depth gas-tight Sediment sampler}

Guang-Ping Liu, born in 1993, is currently a $\mathrm{PhD}$ candidate at National-Local Joint Engineering Laboratory of Marine Mineral Resources Exploration Equipment and Safety Technology, Hunan University of Science and Technology (Xiangtan, China).His research interests include mechanical design and ocean engineering. E-mail:215246290@qq.com

Yong-Ping Jin, born in 1984, obtained his Ph.D. in 2016 from Central South University (Changsha, China).he is a Associate Professor at Hunan University of Science and Technology (Xiangtan, China) leading research on ocean engineering equipment design.

E-mail:jinyongping@hnust.edu.cn

You-duo Peng,born in 1964, obtained his Ph.D. in 2003 from China University of Mining and Technology (Xuzhou, China). Currently, he is a Professor at Hunan University of Science and Technology. (Xiangtan, China) leading research on mechanical dynamics and ocean engineering equipment design.

E-mail:ydpeng1964@163.com

Bu-yan Wan,born in 1964,obtained his Ph.D. in 2011 from Wuhan University of Technology (Wuhan, China). Currently, he is a Research Professor at Hunan University of Science and Technology (Xiangtan, China) leading research on ocean engineering equipment design.

Corresponding author: Yong-Ping Jin E-mail: jinyongping@hnust.edu.c 


\title{
Design and experimental study of pressure compensation system for full-ocean-depth gas-tight Sediment sampler
}

\author{
Guangping Liu, Yongping Jin*, Youduo Peng, Buyan Wan \\ National-Local Joint Engineering Laboratory of Marine Mineral Resources Exploration Equipment and Safety \\ Technology, Hunan University of Science and Technology, Xiangtan, Hunan, 411201
}

\begin{abstract}
Aiming at the requirement of the full-ocean-depth (operating water depth 11000 meters) manned submersible to carry out the gas-tight sampling operation of the abyss seabed sediment, a kind of full-ocean-depth carrier submersible mechanical hand-held, full-ocean-depth gas-tight sediment sampler (GTSS) with the function of pressure-retaining and coring is designed. Firstly, the volume change model of pressure compensator is established, and it is pointed out that the volume of pressure compensator is about $16.14 \%$ equal to the volume of gas-tight sediment sampler (GTSS). Secondly, the pressure compensator is analyzed and calculated, and the relationship between the precharge pressure of the pressure compensator, the nominal volume of the pressure compensator and the pressure holding effect of the gas-tight sediment sampler (GTSS) is studied. The results show that with the increase of gas precharge pressure in the pressure compensator, the final pressure of the sampler also increases. Under the same precharge pressure condition, the larger the nominal volume of the pressure compensator, the greater the final pressure of the sampler. Finally, the air tightness test method is designed by using the developed gas tightness sampler of the full-ocean-depth product, and the change of the final pressure in the gas tight sampler under different precharge pressure is observed. The test results are consistent with the simulation results, indicating the correctness of the pressure compensation system (PCS) model.
\end{abstract}

Keywords: Full-ocean-depth gas-tight sampler, Pressure-retaining, Pressure compensator, Gas tightness

\footnotetext{
${ }^{*}$ Corresponding author.

E-mail address: jinyongping@hnust.edu.cn(Jin Y P)
} 


\section{Introduction}

The full-ocean-depth usually refers to the area that covers the deepest part of the ocean, and the Mariana Trench, which is found at about 11000 meters deep [1-2]. The bottom of the abyss contains abundant medical, mineral and marine living resources, which are important media for human beings to understand and study the evolution of abyss life and the change of abyss environment [3-4]. However, how to collect deep seabed resources quickly, conveniently and effectively in order to obtain first-hand samples of deep seabed resources, fully understand the situation of submarine resources in specific sea areas, and collect resources in different depths of seawater is a major problem in the field of marine resources competition [5-7]. In the deep sea environment, the presence of a large number of pressure-loving organisms in the benthic community is particularly sensitive to changes in external pressure, such as sampling them with traditional non-pressure sampling devices, which can not only guarantee the in situ characteristics of deep seabed resources, but will also have a great impact on the survival of organisms in the seabed area, the seabed environment and other accurate research [8-12]. Therefore, it is urgent to develop a simple, easy-to-operate and reliable deep seabed pressure-retaining sampling device.

At present, the deep seabed sampling and pressure-retaining can be divided into two types, One way of pressure-retaining is to seal valve, the plate valve and the ball valve respectively [13]. Their function is to seal the sampling tube after the sample enters the sampler to ensure that the pressure in the sampling tube will not leak out, such as automatic microbial sampler developed by automatic american Taylor et al AMS [14]; Saegusa et al. developed a multi-bottle airtight sampler WHATS II [15]; Junichi et al. developed a new sequence sampler WHATS III [16]; AndrewBillings et al. developed a SyPRID sampler [17]. This method is simple in structure and easy to realize, but the pressure-retaining effect is not very ideal and can not keep the deep sea pressure in situ. The second way of keeping pressure is accumulator, which is filled with inert gas with certain pressure in advance. In the process of sampler recovery, the accumulator is used to replenish the pressure in real time, such as "Jeff" gas-tight pressure-keeping hydrothermal sampler developed by WHOI Ocean Research Institute [18] ; deep-sea hydrothermal fidelity sampler developed by Zhejiang University [19]; the deep-sea hydrothermal sequence fidelity sampler developed by Zhejiang University [20]; Huang et al. Developed a deep-sea gas-tight water collection system [21-23]. This method requires high sealing requirements for accumulators, but it can achieve keeping effect. It is a commonly used pressure keeping method for deep sea biological sampling equipment at present. 
In this paper, a kind of full-ocean-depth submersible hand-held machine with the function of pressure-retaining and coring is designed. The volume change model of the pressure compensator is established, and the design calculation and simulation analysis of the pressure compensator are carried out. Finally, the air tightness test and the internal pressure test are carried out in the laboratory for the prototype of the gas-tight sediment sampler (GTSS) of the full-ocean-depth. In section 1, the structure and working principle of the gas-tight sediment sampler (GTSS) for the full-ocean-depth sediment are described; In section 2, the volume change model of pressure compensator is established, and it is pointed out that the volume of pressure compensator is about $16.14 \%$ larger than that of gas-tight sediment sampler (GTSS); In section 3, the pressure compensator is analyzed and calculated, and the relationship between the pre-inflated pressure of the pressure compensator, the nominal volume of the pressure compensator and the pressure-retaining effect of the gas-tight sediment sampler (GTSS) is studied. In section 4, the gas tightness test and the internal pressure test of the whole sea deep product gas-tight sediment sampler (GTSS) are carried out by using the developed engineering prototype of the full-ocean-depth product gas-tight sediment sampler (GTSS). The test results verify the feasibility of the design of the full-ocean-depth product gas-tight sediment sampler (GTSS), which will provide strength for the full-ocean-depth carrier submersible abyss seabed sampling operation.

\section{Structure and Working Principle of GTSS}

\subsection{Structure of the GTSS}

The three-dimensional structure of the GTSS system is shown in Fig. 1, including sampling system and PCS. The sampling system includes pressure-retaining cylinder (PRC), tension spring, sampling tube, flap seal valve and trigger mechanism. The bottom end opening of the pressure-retaining cylinder (PRC) is provided with a flap seal valve, which includes a bonnet and valve body, a torsion spring between the bonnet and the valve body; the valve body is sealed with the pressure-retaining cylinder (PRC); the sampling tube is inserted in the pressure-retaining cylinder (PRC), the sampling tube is coaxial with the valve body; a tension spring is installed between the top of the inner hole of the pressure-retaining cylinder (PRC) and the top of the sampling tube; the trigger mechanism is mounted on the side wall of the pressure-retaining cylinder (PRC). The trigger mechanism is installed on the side wall of the pressure-retaining cylinder (PRC). The PCS includes a pressure compensator and an inflatable valve. One end of the pressure compensator is open, and a connecting hole is arranged with the inflatable valve. The other end of the pressure 
compensator is provided with a connecting hole (PRC), and the piston is placed in the pressure connected with the pressure-retaining cylinder compensator.

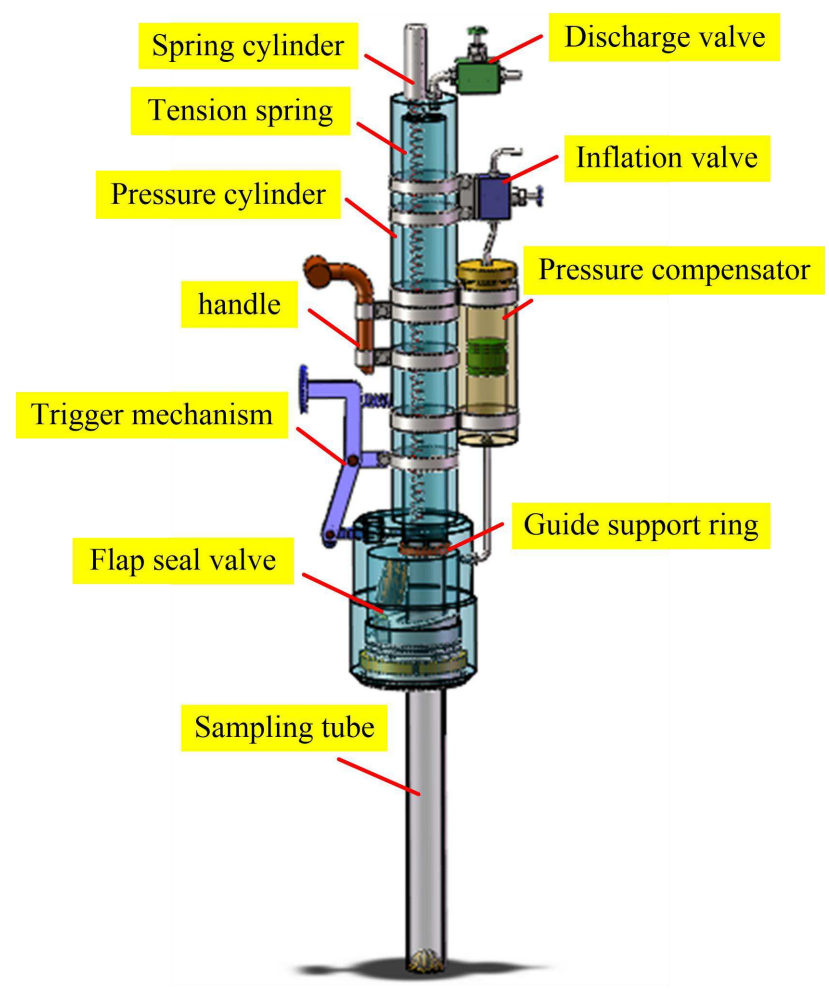

Fig.1Three-dimensional map of the GTSS structure.

\subsection{Working Principle of the GTSS}

The following three steps are involved when obtaining the sediment core with the GTSS :

Lowering: The GTSS is installed on the submersible. Before the submersible is lowered, firstly, the sampling tube is pulled out from the PRC until the trigger mechanism locks the sampling tube. Then, the cavity between the piston of the pressure compensator and the end cover of the compensator is precharged with nitrogen through the inflation valve, so that the piston moves to the bottom position of the pressure compensator. When the submersible is lowered, the piston of the pressure compensator moves downward under the action of seawater pressure until the pressure in the lower cavity and the pressure in the upper cavity of the piston reach equilibrium, as shown in Fig. 2.a.

Sampling: When the submersible reaches the sampling point, grab the GTSS by the manipulator on the submersible, and press the GTSS vertically into the seabed sediment until the sampling tube reaches its maximum stroke. In the sampling process, the water flowing through the sampling tube blocks and compresses the sediment, so a drainage hole is arranged at the top of the sampling tube to allow the water to be discharged from the sampling tube and replaced by the sediment, and 
there is a certain volume of covering water at the top of the sediment core. Then, the trigger mechanism on the GTSS is pushed by the manipulator on the submersible, so that the sampling tube is recovered into the PRC driven by the tension spring, and the flap sealing valve in the airtight sampler is sealed under the action of the torsion spring, as shown in Fig. 2.b.

Recover : After sampling is completed, the GTSS is placed on the sampling basket of the submersible by the manipulator on the submersible.
During the recovery process of the submersible, due to the decrease of the external seawater pressure, the PRC will expand and deform. At this time, the inert gas in the upper cavity of the piston of the PCS will push the piston to move downwards, forcing the seawater in the lower cavity to flow into the PRC through the high-pressure pipe, thus compensating the pressure loss inside the PRC caused by the expansion and deformation of the PRC, as shown in Fig. 2.c.

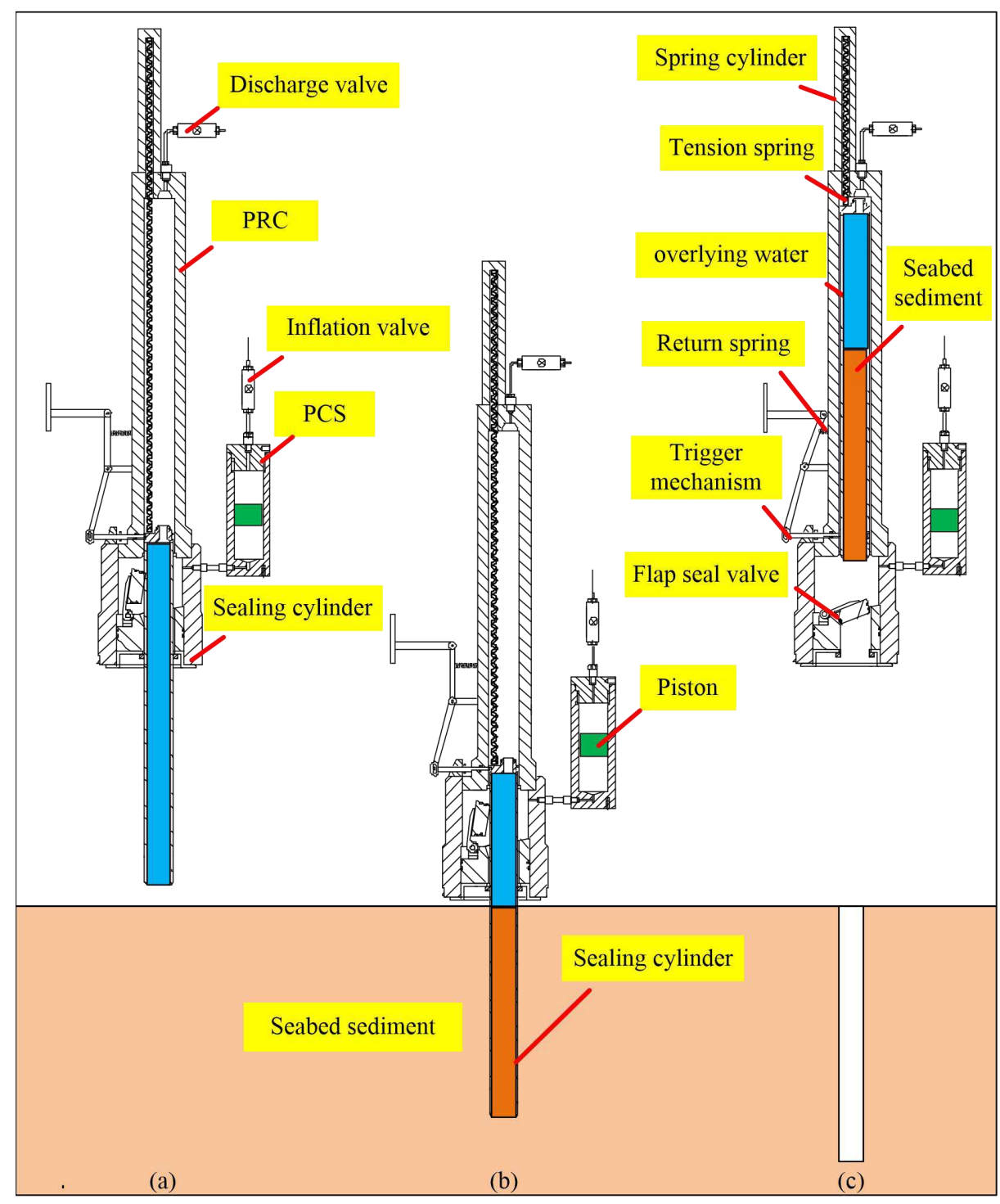

Fig.2 GTSS structure and sampling principle. 


\section{Design and Calculation of PCS}

For the accurate design of the volume of the pressure compensator cavity $V_{B}$, the following factors must be considered: the volume change of seawater produced by pressure change $\Delta V_{Y(Y)}$, the volume change of seawater produced by temperature change $\Delta V_{Y(W)}$, the volume change of gas produced by pressure change $\Delta V_{Q(Y)}$, the volume change of gas produced by temperature change $\Delta V_{Q(W)}$, the leakage of pressure compensator within $48 \mathrm{~h} \Delta V_{L}$, the volume of compensation required for pressure compensator working $\Delta V_{G}$ and the volume change of pressure compensator working with pressure and temperature change $\Delta V_{B G}$. According to the knowledge of fluid mechanics, the volume change model of pressure compensator cavity $V_{B}$ is established.

$V_{B}=\Delta V_{Y(Y)}+\Delta V_{Y(w)}+\Delta V_{Q(Y)}+\Delta V_{Q(W)}+\Delta V_{L}+\Delta V_{G}+\Delta V_{B G}$

$\Delta V_{Y(Y)}=\beta V_{Y} P_{J}$

$V_{Y}>V_{1}+V_{2}+V_{3}$

The $\beta$ is volume compression coefficient, $\beta=0.5 \times 10^{-9} \mathrm{~Pa}$; the $V_{Y}$ is the volume of the GTSS; the $P_{J}$ is the hydrostatic pressure; the $V_{l}$ is the volume of the PRC; the $V_{2}$ is the volume of the sealing cylinder; and the $V_{3}$ is the volume of the spring cylinder. Because the inner diameter of the spring cylinder is very small, the volume of the spring cylinder is negligible.

$$
\Delta V_{Y(W)}=\alpha \Delta \mathrm{t} V_{Y}
$$

The $\alpha$ is the coefficient of body expansion temperature, $\alpha=$ is $9 \times 10^{-4}{ }^{\circ} \mathrm{C}$, and the $\Delta t$ is the temperature change. When the GTSS is lowered to 11000 meters below the sea floor, the gas volume can be minimized to a negligible extent, that is:

$$
\Delta V_{Q(Y)}=0
$$

$\Delta V_{Q(W)}=V_{Y} K_{X}$

The $K_{X}$ is gas-liquid coefficient, $K_{X}=5 \%$.

$\Delta V_{L}$ and $\Delta V_{G}$ are negligible in designed airtight samplers, $\Delta V_{B G}$ can be calculated by Eq. (7).

$$
\Delta V_{B G}=V_{B} C
$$

Where $C$ is the volume change coefficient of pressure compensator, it can be calculated by Eq. (8)

$C=\Sigma \Delta V / V_{Y}$

Where $\Sigma \Delta V$ is the balanced seawater volume in the pressure compensator, $\Sigma \Delta V$ can be calculated by Eq. (9)

$$
\Sigma \Delta V=\Delta V_{Y(Y)}+\Delta V_{Y(W)}+\Delta V_{Q(W)}
$$

Eq. (1) -Eq. (9) can be used to calculate the volume of the pressure adaptive equalizer $V_{B}$ as follows:

$$
V_{B} \geq \frac{C}{1-C} V_{Y}=\frac{\beta P_{J}+\alpha \Delta \mathrm{t}+K_{X}}{1-\left(\beta P_{J}+\alpha \Delta \mathrm{t}+K_{X}\right)}\left(V_{1}+V_{2}\right)
$$

Based on the research object of "the development of the full-ocean-depth gas-tight Sediment sampler (GTSS) ", the materials used in the high pressure cavity of the GTSS are all TC4 titanium alloys. The design parameters of the GTSS are shown in Table 1. 
Table 1 Design parameters of GTSS.

\begin{tabular}{cc}
\hline Parameters & Value \\
\hline Inner diameter of PRC & $56 \mathrm{~mm}$ \\
Outside diameter of PRC & $86 \mathrm{~mm}$ \\
Height of PRC & $600 \mathrm{~mm}$ \\
Inner diameter of sealing cylinder & $115 \mathrm{~mm}$ \\
Outer diameter of sealing cylinder & $175 \mathrm{~mm}$ \\
Height of sealing cylinder & $100 \mathrm{~mm}$ \\
Height of pressure compensator & $300 \mathrm{~mm}$ \\
Temperature variation $\Delta t$ & $35{ }^{\circ} \mathrm{C}$ \\
Hydrostatic pressure $P_{J}$ & $110 \mathrm{MPa}$ \\
\hline
\end{tabular}

Substituting the design parameters in Table 1 into Eq. (8) can be obtained

$$
\left\{\begin{array}{l}
V_{B} \geq 16.14 \% V_{Y} \\
V_{Y}>2500 m l
\end{array}\right.
$$

It can be known from Eq. (11) that when the volume of the GTSS is $2500 \mathrm{ml}$ and the water depth is $11000 \mathrm{~m}$, the volume of the pressure compensator chamber is about $16.14 \%$ or more of the volume of the GTSS, that is, $403.5 \mathrm{ml}$ or more.

\section{Analysis, Calculation and Simulation of} PCS

\subsection{Analysis and calculation of PCS}

In the process of sampling and recovery of GTSS, due to the continuous decline of external environmental pressure, pressure difference will occur inside and outside the PRC, and under the action of pressure difference, the PRC will produce certain elastic volume expansion. At the same time, the deformation of elastomer such as sealing cylinder and spring cylinder will lead to the decrease of sample pressure in the PRC, resulting in the loss of gas phase dissolved component, the change of oxidation state of valence ion and the decomposition of organic component, and even the partial biological death. Therefore, it is necessary to compensate the pressure of the PRC to keep the sample pressure in the PRC basically unchanged. After GTSS and recycling, the GTSS will be put into the freezer immediately to keep the temperature of the sampler basically the same as the original temperature of the sample, so the influence of temperature on the volume change of elastomer such as PRC and pressure compensation device can be ignored. The flow chart of the optimal design program of the PCS is shown in Fig. 3. 


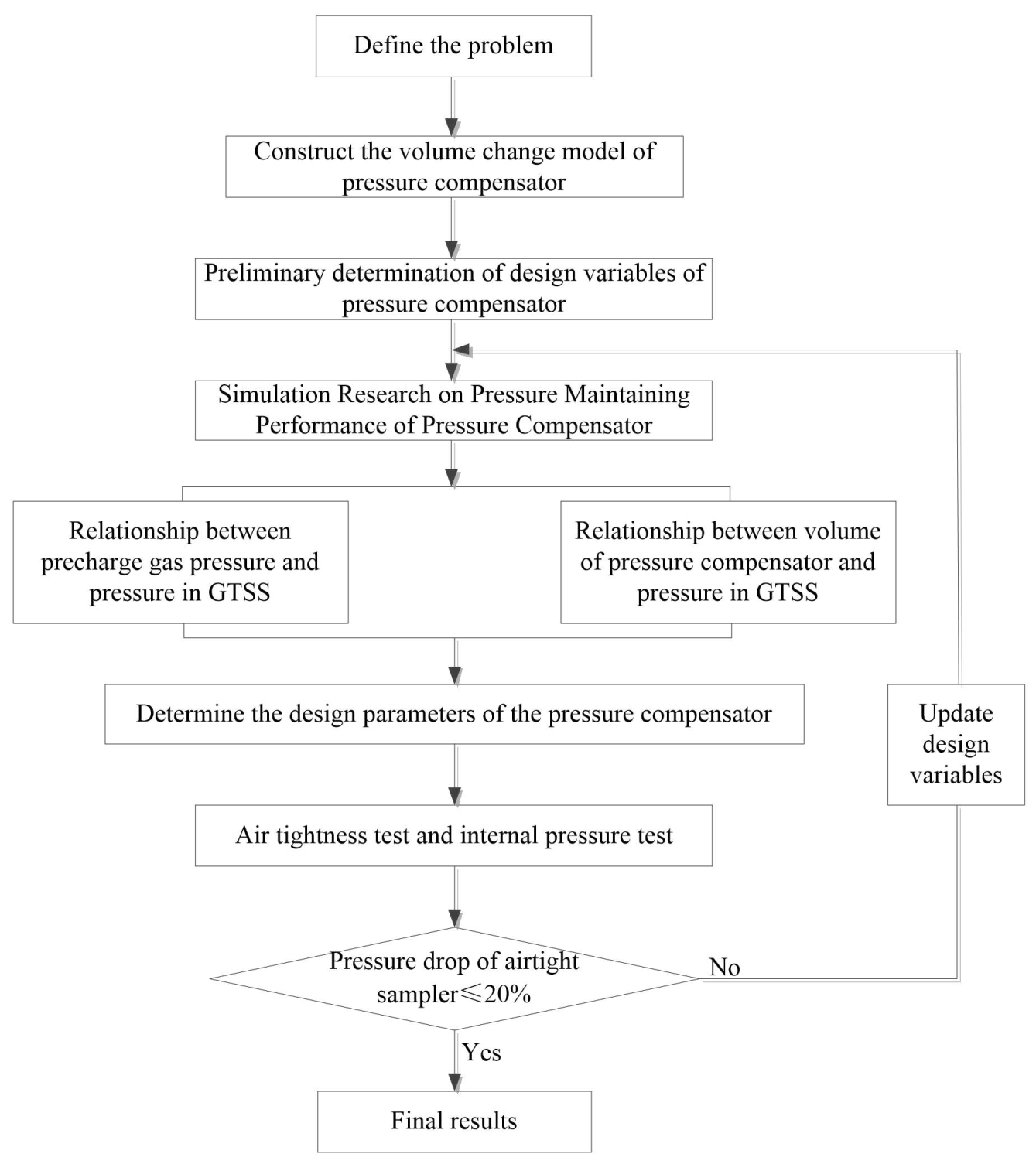

Fig.3 Flow chart of optimal design program for PCS.

The movement process of the piston in the pressure compensation device is shown in Fig. 4. Before the GTSS is lowered, the position of the piston in the pressure compensator is shown in Fig. 4.a, at which time the volume of nitrogen is the largest. When the GTSS is under, the piston position in the pressure compensator is shown in
Fig. 4.b, and the pressures at both ends of the piston are kept equal. When the GTSS completes sampling, during the recovery process, the environmental pressure gradually decreases, and the inert gas in the piston cavity of the pressure compensator will push the piston to the left, while the piston position in the pressure compensator is shown in Fig. 4.c. 


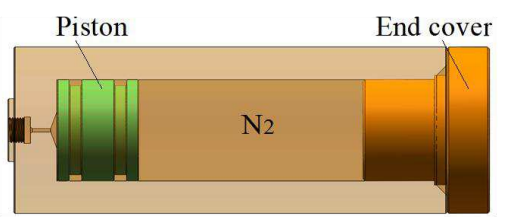

(a)

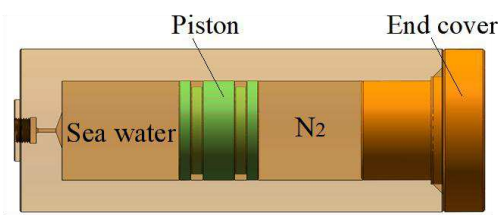

(b)

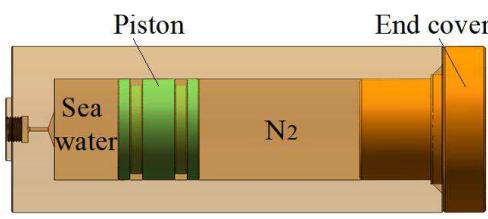

(c)

Fig.4 Motion process of pressure compensator piston.

Assume that the inner diameter of the high-pressure cavity is $r_{0}$, the outer diameter is $r_{i}$, the height is $h$, the volume is $V$, the seawater pressure at the sampling place is $P_{1}=110 \mathrm{MPa}$, and the materials used in the high-pressure cavity of the GTSS are all TC4 titanium alloy, and the elastic modulus of TC4 titanium alloy is $E=113 \mathrm{GPa}$ and Poisson's ratio is $\mu=0.34$. According to the elastic theory, the radial and axial deformation formulas of the high-pressure cavity under the action of internal and external pressure difference are:

The radial deformation is:

$$
\Delta u_{b}=\frac{r_{0}^{2} P_{1}}{r_{0} E\left(r_{i}^{2}-r_{0}^{2}\right)}\left[r_{0}^{2}(1-2 \mu)+r_{i}^{2}(1+\mu)\right]
$$

The axial deformation is:

$$
\Delta L_{b}=\frac{r_{0}^{2} P_{1} h(1-2 \mu)}{E\left(r_{i}^{2}-r_{0}^{2}\right)}
$$

The volume deformation is:

$$
\Delta V_{b}=\pi\left(r_{0}+\Delta u_{b}\right)^{2}\left(h+\Delta L_{b}\right)-\pi r_{0}{ }^{2} h
$$

Given that the volume elastic modulus of seawater is $E_{1}=2.4 \mathrm{GPa}$, the pressure drop in the high-pressure chamber caused by the volume expansion of the high-pressure chamber is:
$\Delta P_{b}=\frac{\Delta V_{b}}{V} \cdot E_{1}$

According to Eq. (12) Eq. (15), it can be obtained that the volume change of the PRC is $\Delta V_{1}=17 \mathrm{ml}$, the pressure drop is $\Delta P_{1}=28.1 \mathrm{MPa}$, the volume change of the sealing cylinder is $\Delta V_{2}=12 \mathrm{ml}$, and the pressure drop is $\Delta P_{2}=28.1 \mathrm{MPa}$. Let the volume change of the pressure compensator be $\Delta V_{3}$ and the pressure drop be $\Delta P_{3}$, and the pressure of the sample in the PRC after sampling and recovery is $P$. According to the technical requirements of "the development of the full-ocean-depth gas-tight Sediment sampler (GTSS)", the pressure change of pressure-holding samples is less than or equal to $20 \%$, namely:

$$
\left\{\begin{aligned}
\Delta V & \geq \Delta V_{1}+\Delta V_{2}+\Delta V_{3} \\
P & \geq 0.8 p_{1}
\end{aligned}\right.
$$

\subsection{Simulation study on the holding performance of PCS}

In this paper, the inner diameters of pressure compensators are simulated as $30 \mathrm{~mm}, 40 \mathrm{~mm}$, $50 \mathrm{~mm}, 60 \mathrm{~mm}$ and $70 \mathrm{~mm}$, respectively. The relationship between the pre-inflation pressure of 
pressure compensators, the nominal volume of pressure compensators and the holding effect of GTSS is analyzed by using Matlab 2016. The simulation parameters of pressure compensators are shown in Table 2.

Table 2 Simulation parameters of pressure compensator.

\begin{tabular}{cccccc}
\hline inner-diameter $(\mathrm{mm})$ & 30 & 40 & 50 & 60 & 70 \\
\hline Volume $(\mathrm{mL})$ & 210 & 380 & 590 & 850 & 1150 \\
\hline
\end{tabular}

Assuming that the nominal volume of the pressure compensator is $V_{3}$ and the precharge pressure is $P_{0}$, the GTSS dives 11,000 meters into the compensator nitrogen volume:

$V_{x}=\frac{P_{0} \cdot V_{3}}{P_{1}}$

According to the equation of state of gas, the pressure value in the compensated GTSS is:

$P=\frac{P_{1} \cdot V_{x}}{V_{x}+\Delta V}$

The relation curve between the precharge pressure of the pressure compensator and the pressure value in the GTSS is shown in Fig. 5. When the volume of the pressure compensator is the same, the greater the pressure of the precharged gas in the pressure compensator, the corresponding increase of the pressure in the GTSS.When the precharge pressure in the pressure compensator is greater than $20 \mathrm{MPa}$, the pressure in the GTSS increases slowly; When the precharged gas pressure in the pressure compensator is the same, the pressure in the GTSS increases with the increase of the nominal volume of the pressure compensator. When the nominal volume of the pressure compensator is greater than $590 \mathrm{ml}$, the pressure in the GTSS increases slowly; Because the precharge gas of the pressure compensator is nitrogen, considering the safety of operation, this paper chooses the precharge pressure of the pressure compensator to be $20 \mathrm{MPa}$. It can be seen from Fig. 5 that the precharging pressure in the pressure compensator is $20 \mathrm{MPa}$. when the nominal volume of the pressure compensator is $380 \mathrm{ml}$, the pressure in the GTSS is $94.2 \mathrm{MPa}$, and the pressure drop in the GTSS is $14.3 \%$. When the nominal volume of the pressure compensator is $590 \mathrm{ml}$, the pressure in the GTSS is $102.3 \mathrm{MPa}$ and the pressure drop in the GTSS is $7.0 \%$. As the nominal volume of the pressure compensator increases, the weight of the pressure compensator increases accordingly. Considering that other cavities in the GTSS need compensation, in the design of the pressure compensator, the volume of the pressure compensator is $590 \mathrm{ml}$, the precharge pressure is $20 \mathrm{MPa}$, and the corresponding inner diameter of the pressure compensator is $50 \mathrm{~mm}$. 


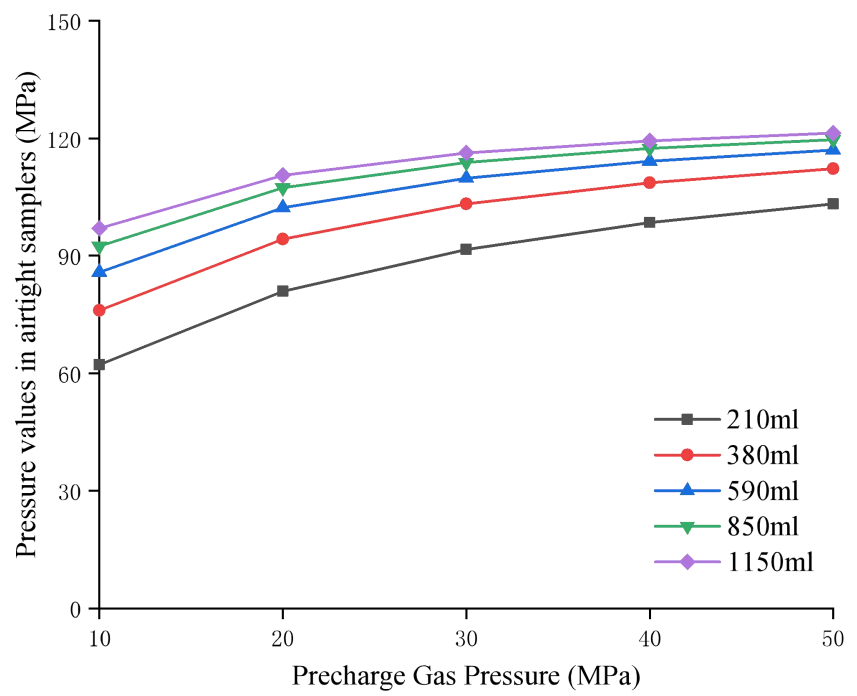

Fig. 5 Relationship curve between precharge pressure of pressure compensator and pressure in GTSS.

\section{Experimental study on air tightness of} GTSS

In order to verify the airtightness of the GTSS, our research group conducted the airtightness test of the whole GTSS in the laboratory. The test schematic diagram is shown in Fig. 6. Compressed air is used as the driving power source, gas booster pump is used as the pressure source, and air is used as the pressurized medium. The output air pressure is proportional to the driving air source pressure. By adjusting the pressure of the driving gas source, the corresponding pressurized gas pressure can be obtained. When the driving gas source pressure and the pressurized gas pressure are balanced, the pneumatic booster pump stops pressurizing, and the gas pressure of the output gas is stabilized at the preset pressure.

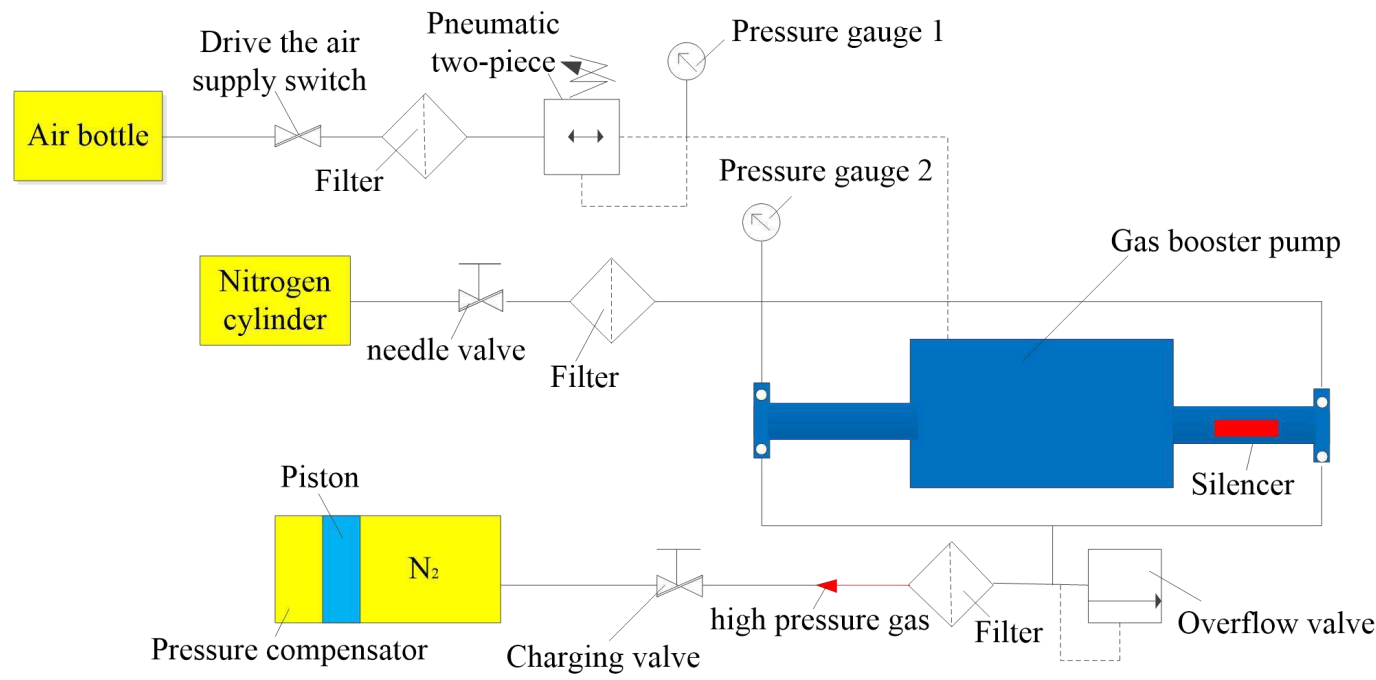

Fig. 6 Schematic diagram of air tightness test of GTSS. 
Firstly, open the flap sealing valve at the bottom of the GTSS through the ejector rod, inject enough water into the GTSS, and connect the pressurizing pump with the high pressure valve through the high pressure pipe; Open the high-pressure valve, inflation valve, close the unloading valve, add water to the GTSS through the pressurizing pump, push the piston in the pressure compensator to move towards the inflation valve, and exhaust the air in the pressure compensator; When the pressure gauge on the pressure pump has a value, it indicates that the piston has been pushed to the top near the inflation valve, and the pressurization is stopped. by opening the high pressure valve in the pressure pump, the pressure of the GTSS is removed; Connect the pipeline of the gas pressurization system, and connect the high-pressure pipe of the high-pressure gas outlet to the inflation valve on the pressure compensator; Unscrew the control valve of air bottle and adjust the pressure reducing valve to adjust the pressure of compressed air source to $0.2 \mathrm{MPa}$, unscrew the control valve of nitrogen bottle and adjust the pressure reducing valve to adjust the nitrogen pressure to $10 \mathrm{MPa}, 20 \mathrm{MPa}, 30 \mathrm{MPa}, 40 \mathrm{MPa}$ and $50 \mathrm{MPa}$, and close the charging valve; Close the control valves of air bottle and nitrogen bottle, open the high-pressure unloading ball valve, and bleed the pressurization system pipeline, so that the high-pressure gas can be discharged; After the discharge, remove the high-pressure pipe between the pressurization system and the inflation valve, and close the high-pressure unloading valve for the next inflation; Close the transfer valve and inflation valve, connect the high-pressure pipeline between the manual pressure pump and the sample unloading valve on the sampler, open the sample unloading valve, manually press the pressure pump, and observe the pressure value of the pressure gauge on the pressure pump; Pressurize the GTSS system to $110 \mathrm{MPa}$ by the pressurizing pump, and keep the pressure for 12 hours (it takes about $8 \sim 12$ hours for the GTSS to go from the seabed to the coast), and observe the pressure value of the pressure gauge on the pressurizing pump; Continue to pressurize the GTSS to $127 \mathrm{MPa}$, keep the pressure for 12 hours, and observe the pressure value of the pressure gauge on the pressurizing pump; Open the transfer valve slowly, start to relieve pressure, and after ensuring no pressure inside, disassemble the pressurization pipeline and arrange the test tools. Fig. 7 is the air tightness test diagram of GTSS. 


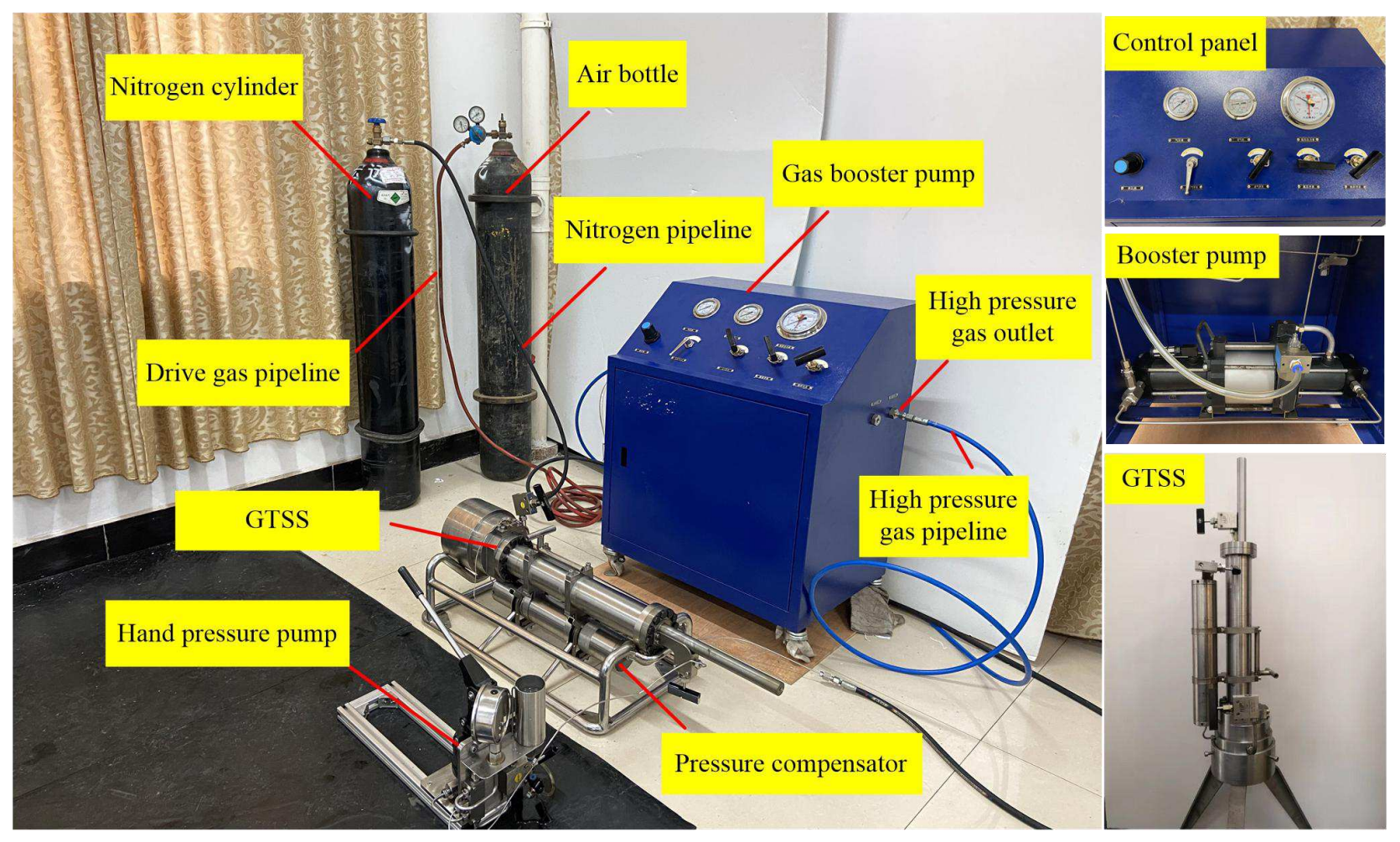

Fig. 7 Air tightness test of GTSS.

In order to verify the pressure retaining ultra-high pressure vessel (maximum working performance of the GTSS, the internal pressure test pressure for ultra high pressure vessels), is the of the GTSS was carried out in the laboratory. The internal pressure test pressure coefficient, and is schematic diagram and field diagram of the internal pressure test of the GTSS are shown in Fig. 8 and Fig.9. Use the following equation to carry out internal pressure chamber test: $p_{T}=\eta p \frac{R_{p 0.2}}{R_{p 0.2}^{t}}$

where $p(\mathrm{MPa})$ is the design pressure of the taken as $1.15, R_{p 0.2}(\mathrm{MPa})$ is the lower limit of the yield strength of the material at the test temperature, and $R_{p}^{t} 0.2(\mathrm{MPa})$ is the lower limit of the yield strength of the material at the design temperature. The internal pressure test pressure is thus calculated as:

$$
p_{T}=\eta p \frac{R_{p 0.2}}{R_{p 0.2}^{t}}=127 \mathrm{MPa}
$$




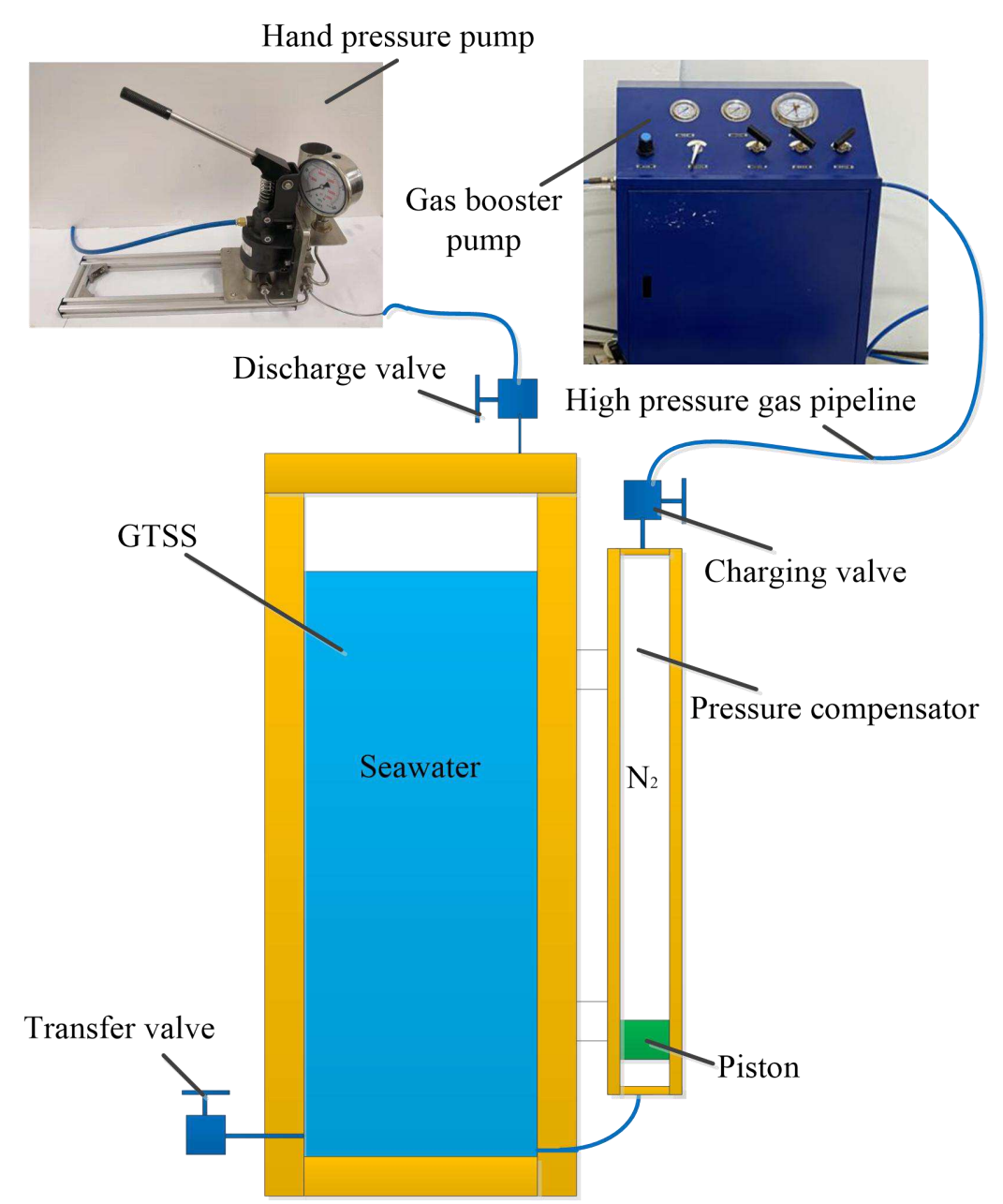

Fig. 8 Schematic diagram of internal pressure test of GTSS.

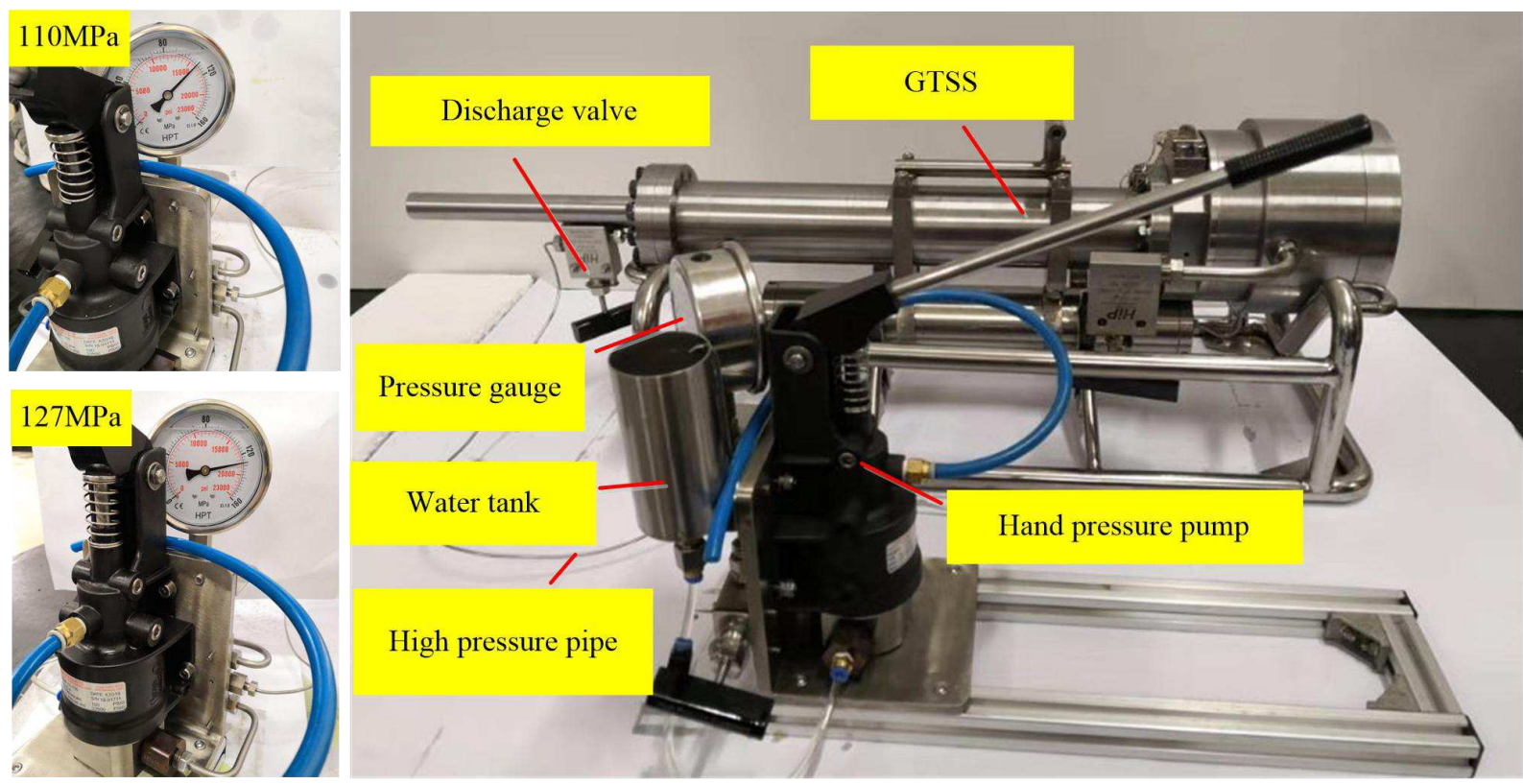

Fig. 9 Internal pressure test of GTSS. 


\section{Experimental results and discussion}

The air tightness verification test results of the GTSS are shown in Table 3. It can be seen that when the precharging pressure of $1 \#$ is $10 \mathrm{MPa}$, the GTSS is kept under the pressure environment of $115 \mathrm{MPa}$ and $127 \mathrm{MPa}$ for 12 hours, and the pressure drop in the GTSS is $25 \%$ and $31 \%$, respectively, both of which are greater than the pressure drop required by the project and less than $20 \%$. Test 2\# 5\#, GTSS under $115 \mathrm{MPa}$ and 127 MPa pressure environment for 12 hours, the pressure drop in GTSS is less than 20\%, which meets the project requirements.

Table 3 Air tightness test results of GTSS.

\begin{tabular}{|c|c|c|c|c|}
\hline Numbering & Projects & $\begin{array}{l}\text { Precharged nitrogen pressure } \\
\qquad(\mathrm{MPa})\end{array}$ & Pressur & GTSS \\
\hline \multirow{2}{*}{$1 \#$} & Start pressure maintaining & \multirow{2}{*}{10} & 110 & 127 \\
\hline & End pressure maintaining & & 82.5 & 87.5 \\
\hline \multirow{2}{*}{$2 \#$} & Start pressure maintaining & \multirow{2}{*}{20} & 110 & 127 \\
\hline & End pressure maintaining & & 100.0 & 110 \\
\hline \multirow{2}{*}{$3 \#$} & Start pressure maintaining & \multirow{2}{*}{30} & 110 & 127 \\
\hline & End pressure maintaining & & 107.5 & 117.5 \\
\hline \multirow{2}{*}{ 4\# } & Start pressure maintaining & \multirow{2}{*}{40} & 110 & 127 \\
\hline & End pressure maintaining & & 112.5 & 125 \\
\hline \multirow{2}{*}{$5 \#$} & Start pressure maintaining & \multirow{2}{*}{50} & 110 & 127 \\
\hline & End pressure maintaining & & 115 & 127.5 \\
\hline
\end{tabular}

Fig. 10 is a comparison diagram of the theoretical calculated value and the actual value of the final pressure in the GTSS under the pressures of $110 \mathrm{MPa}$ and $127 \mathrm{MPa}$ and the precharging pressures of $10 \mathrm{MPa}, 20 \mathrm{MPa}, 30 \mathrm{MPa}, 40 \mathrm{MPa}$ and $50 \mathrm{MPa}$. It can be seen from the figure that the change trend of the theoretical calculation value and the actual value of the final pressure in the GTSS is basically consistent, and the maximum deviation is
$3 \%$, which shows that the pressure compensator model constructed in this paper is feasible. Under the pressure of $110 \mathrm{MPa}$ and $127 \mathrm{MPa}$, the theoretical calculation value of the GTSS is slightly higher than the actual value. The reason for this phenomenon is that the volume change of the spring cylinder and other cavities is not considered in the theoretical calculation. 


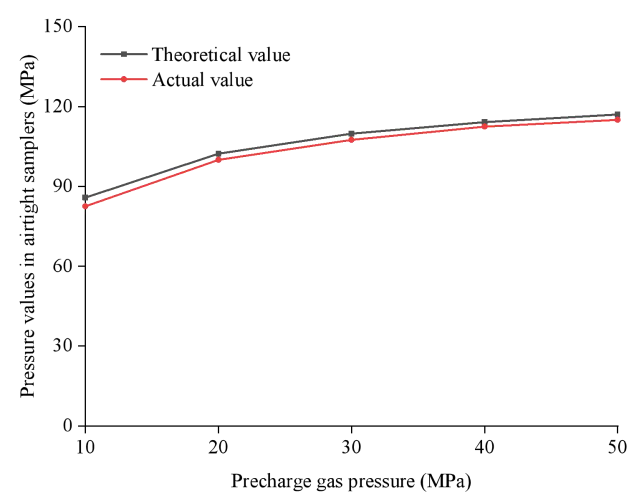

(a) $110 \mathrm{MPa}$

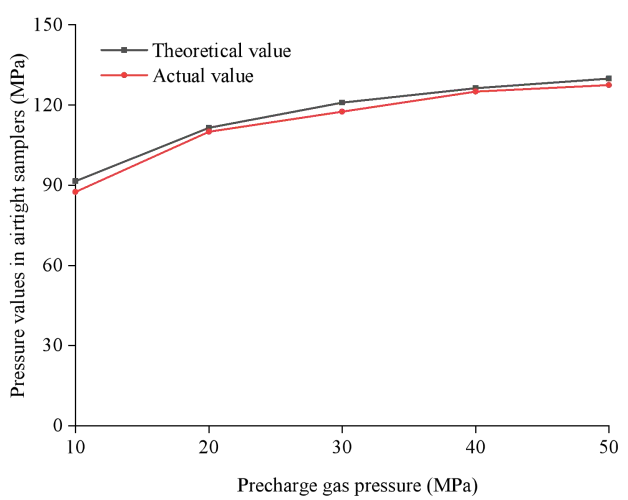

(b) $127 \mathrm{MPa}$

Fig. 10 Actual and theoretical values of pressure in GTSS under different precharging pressures

\section{Conclusion}

(1) A mechanical hand-held GTSS with the function of holding pressure and coring is designed. The working water depth reaches 11,000 meters, and the underwater automatic airtight sealing function can be completed by one trigger of the manipulator, which solves the problems that the traditional sampler adopts complex hydraulic system, which affects the in-situ characteristics of sediments and the working water depth is 7,000 11,000 meters for sampling.

(2) The volume change model of pressure compensator of GTSS is established, and it is pointed out that the volume of pressure compensator should be greater than or equal to $16.14 \%$ of the volume of GTSS. The relationship between the precharging pressure of the pressure compensator, the nominal volume of the pressure compensator and the holding effect of the GTSS is studied, and the simulation analysis is carried out. Finally, the volume of the pressure compensator is $590 \mathrm{ml}$, the precharging pressure is $20 \mathrm{MPa}$, and the corresponding inner diameter of the pressure compensator is $50 \mathrm{~mm}$.

(3) The air tightness test and internal pressure test of the GTSS are carried out by using the developed engineering prototype of the GTSS. The test results are consistent with the simulation results, and the maximum deviation is $3 \%$. The feasibility of the GTSS based on automatic pressure compensation designed in this paper is verified, which will provide strong support for the deep seabed sampling operation of the full-ocean-depth manned submersible.

\section{CRediT authorship contribution statement}

Guangping Liu: Writing original draft, Conceptualization, Methodology, Validation. 
Yongping Jin: Conceptualization, Supervision Funding acquisition, , Writing - review \& editing. Youduo Peng: Data curation, Writing - review \& editing. Buyan Wan: Writing - review \& editing.

\section{Author Details}

National-Local Joint Engineering Laboratory of Marine Mineral Resources Exploration Equipment and Safety Technology, Hunan University of Science and Technology, Xiangtan, Hunan, 411201

\section{Declaration of Competing Interest}

The authors declare that they do not have any financial or non-financial conflict of interests.

\section{Acknowledgments}

This work is supported by the National Natural Science Foundation of China (Grant No.51705145, 51779092), and the National Key Research and Development Program of China (Grant No.2016YFC0300502, 2017YFC0307501), Hunan Province Natural Science Foundation (Grant No.2019JJ50182) and Scientific Research Fund of Hunan Provincial Education Department (Grant No.18B205)

\section{References}

[1] Jamieson, A.J., 2015. The Hadal Zone: Life in the Deepest Oceans. Cambridge 635 University Press, London.

[2] Gallo, N. D. , Cameron, J. , Hardy, K. , Fryer, P. , Bartlett, D. H. , \& Levin, L. A. . (2015). Submersible- and lander-observed community patterns in the mariana and new britain trenches: influence of productivity and depth on epibenthic and scavenging communities. Deep-Sea Research Part I, 99, 119-133.

[3] Jamieson, A.J., 2016. Landers: Baited cameras and traps. In: Clark, Malcolm R. (Ed.), Biological Sampling in the Deep Sea.

[4] Leon-Zayas, Peoples L., Biddle, J.F., Podell, S., Novotny, M., Cameron, J., et al., 2017. The metabolic potential of the single cell genomes obtained from the Challenger Deep, Mariana Trench within the candidate superphylum Parcubacteria (OD1). Environ. Microbiol. 19, 2769-2784.

[5] Peoples, L.M., Donaldson, S., Osuntokun, O., Xia, Q., Nelson, A., Blanton, J., et al., 2018. Vertically distinct microbial communities in the Mariana and Kermadec trenches. PLoS One 13, e0195102.

[6] Tarn, J., Peoples, L.M., Hardy, K., Cameron, J., Bartlett, D.H., 2016. Identification of free-living and particle-associated microbial communities present in hadal regions of the Mariana Trench. Front. Microbiol. 7, 1-15.

[7] Watling, L. , Guinotte, J., Clark, M. R. , \& Smith, C. R., 2013. A proposed biogeography of the deep ocean floor. Progress in Oceanography, 111(apr.), 91-112.

[8] Jamieson, A.J., Fujii, T., Mayor, D.J., Solan, M., Priede, I.G., 2010. Hadal trenches: the ecology of the deepest places on Earth. Trends Ecol. Evol. 25, 190-197.

[9] Glud, R.N., Wenzhofer, F., Middelboe, M., Oguri, K., Turnewitsch, R., Canfield, D.E., Kitazato, H., 2013. High rates of microbial carbon turnover in sediments in the deepest oceanic trench on Earth. Nature Geoscience 6, 284-288.

[10] Li, Y. , Peng, J. , Huang, C. , \& Wang, M., 2018. Experimental study on a sampling technique based 
on a freeze-sediments valve for deep-sea microorganism. Applied Ocean Research, 82, 470-477.

[11] Tang, G. , \& Wang, J., 2019. A comparative study of energy performance of hydrostatic seafloor sediment samplers and a new high-efficiency sampler. Applied Ocean Research, 83, 1-8.

[12] Logan, M. Peoples., Matthew, Norenberg., David, Price., et al., 2019. A full-ocean-depth rated modular lander and pressure-retaining sampler capable of collecting hadal-endemic microbes under in situ conditions. Deep Sea Research Part I: Oceanographic Research Papers, 143, 50-57.

[13] Liu, G.P., Jin, Y.P., Peng, Y.D., et al., 2018. Multi-objective Optimization Design of Flap Sealing Valve Structure for Deep Sea Sediment Sampling. Journal of Vibration Testing and System Dynamics, 2(3): 281-290.

[14] Taylor, C. D. , Doherty, K. W. , Molyneaux, S. J. , Iii, A. T. M. , Billings, J. D. , \& Engstrom, I. B. , et al., 2006. Autonomous microbial sampler (ams), a device for the uncontaminated collection of multiple microbial samples from submarine hydrothermal vents and other aquatic environments. Deep-Sea Research Part I, 53(5), 894-916.

[15] Saegusa, S. , Tsunogai, U. , Nakagawa, F. , \& Kaneko, S., 2010. Development of a multibottle gas-tight fluid sampler WHATS II for japanese submersibles/rovs. Geofluids, 6(3), 234-240.

[16] Junichi, M. , Akiko, M. , Yohei, M. , Naoya, E. , Saki, T. , \& Jun-Ichiro, I. , et al., 2017. WHATS-3: an improved flow-through multi-bottle fluid sampler for deep-sea geofluid research. Frontiers in
Earth ence, 5, 45.

[17] Billings, A., Kaiser, C., Young, C. M., Hiebert, L. S., Cole, E., \& Wagner, J. K. S., et al., 2016. Syprid sampler: a large-volume, high-resolution, autonomous, deep-ocean precision plankton sampling system. Deep Sea Research Part II Topical Studies in Oceanography.

[18] Jeffrey, S., Seewald, and, Kenneth, \& W., et al., 2002. A new gas-tight isobaric sampler for hydrothermal fluids. Deep Sea Research Part I Oceanographic Research Papers.

[19] Chen, Y. , Wu, S. , Xie, Y. , Yang, C. , \& Zhang, J., 2008. A novel mechanical gas-tight sampler for hydrothermal fluids. IEEE Journal of Oceanic Engineering, 32(3), 603-608.

[20] Wei, L. , Canjun, Y. , Shijun, W. U. , Yingjun, X. , \& Ying, C., 2008. Design of novel high pressureresistant hydrothermal fluid sample valve. Chinese Journal of Mechanical Engineering, 21(1), 72-76.

[21] Huang, H., Yang C., Chen S., Chen D., Sun C., \& Niu W., et al., 2012. Novel gas-tight multi-sampler for discrete deep-sea water. Chinese Journal of Mechanical Engineering.

[22] Chen, J. , Chen, Y. , Sheng, Q. , Gu, L. , Chen, Y. , \& Yang, J. . 2014. A novel active seafloor pressure-retained multitube sediment corer. Marine Technology Society Journal, 48(3), 43-56.

[23] Huang, H. , Yuan, Z. , Kang, W. , Xue, Z. , Chen, X. , \& Yang, C. , et al. 2014. Study of the sealing performance of tubing adapters in gas-tight deep-sea water sampler. International Journal of Naval Architecture and Ocean Engineering, 6( 3), 749-761. 


\section{Figures}

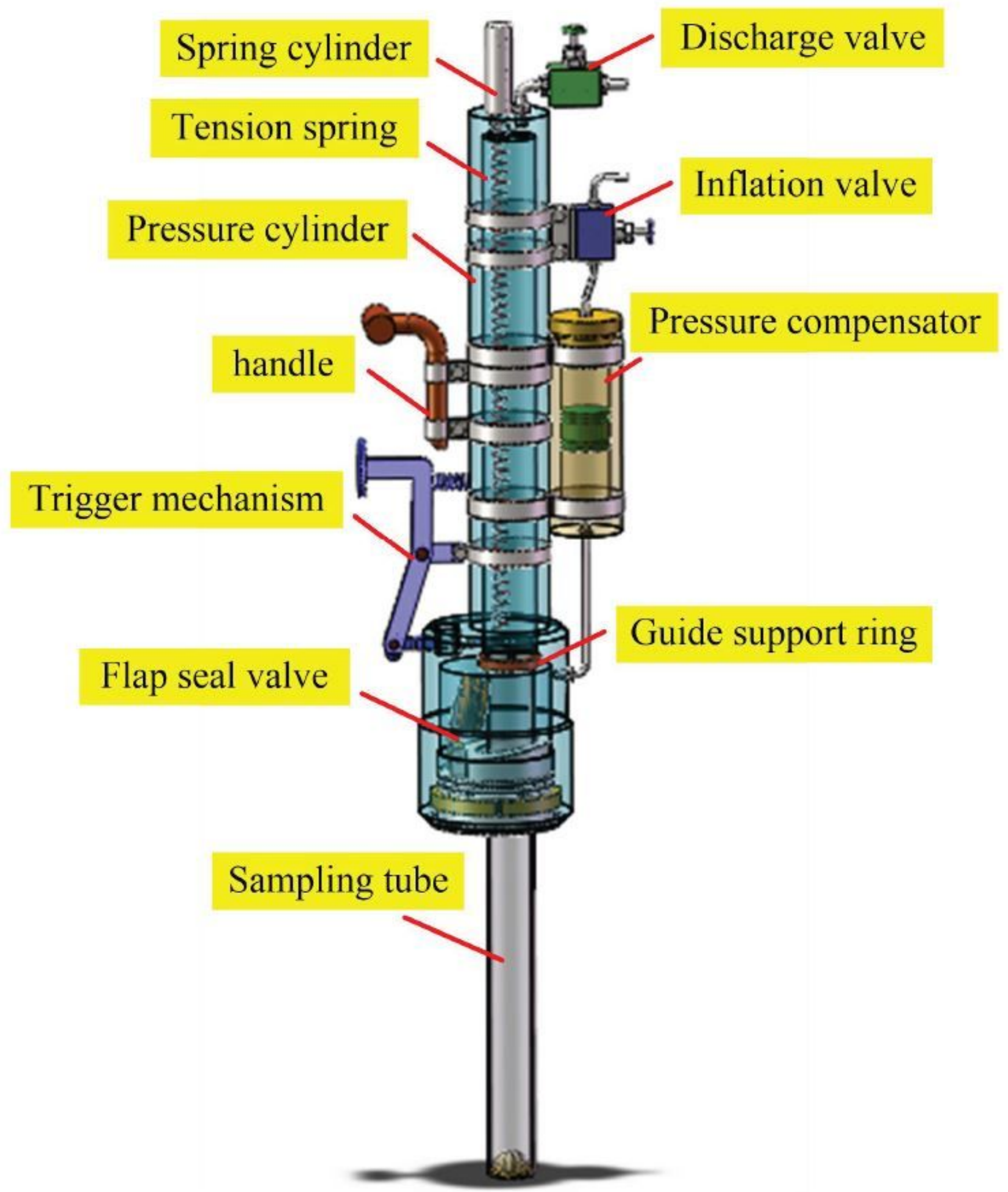

Figure 1

Three-dimensional map of the GTSS structure. 


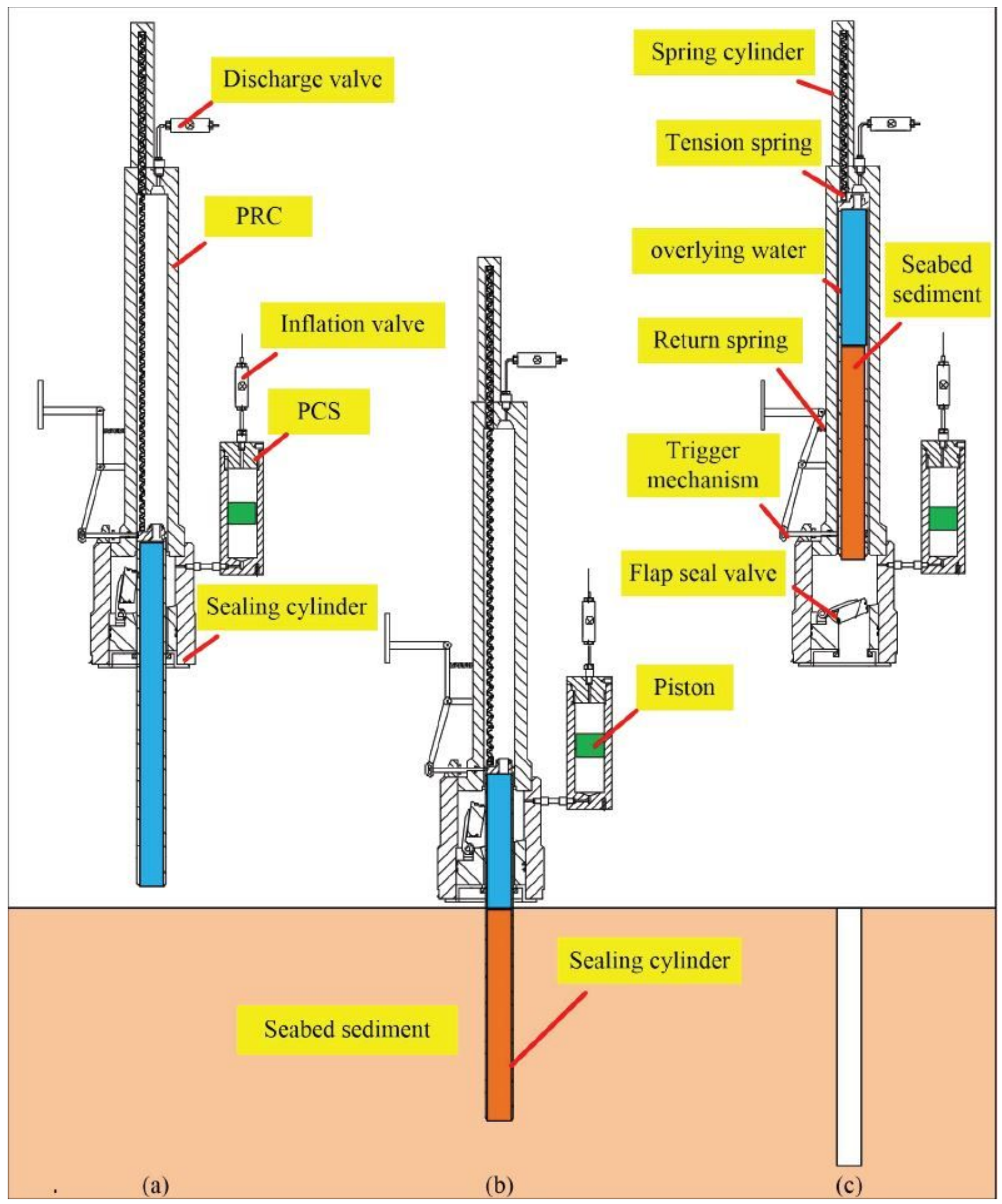

Figure 2

GTSS structure and sampling principle. 


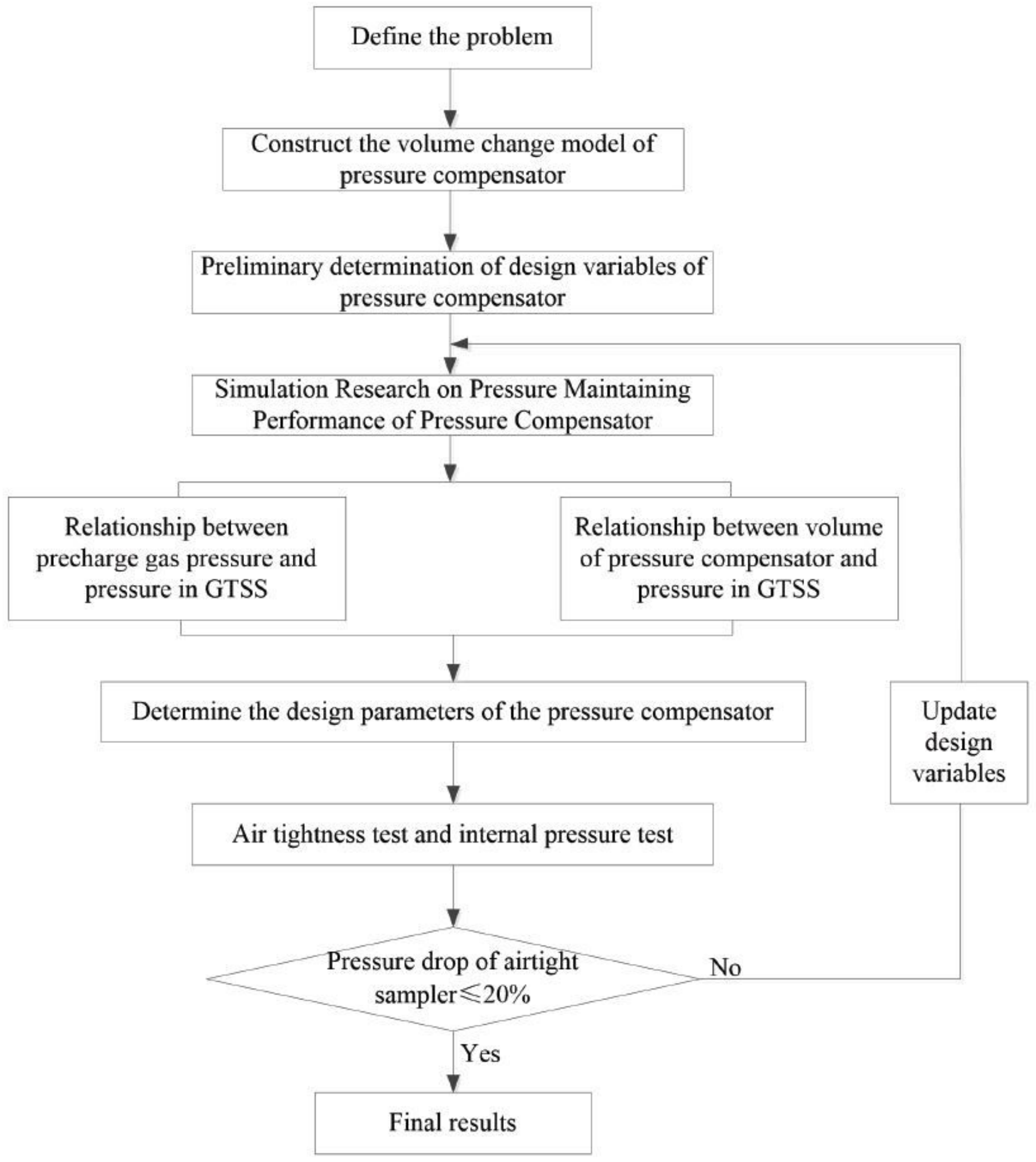

Figure 3

Flow chart of optimal design program for PCS. 


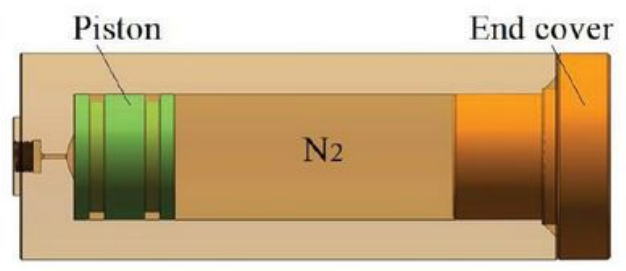

(a)

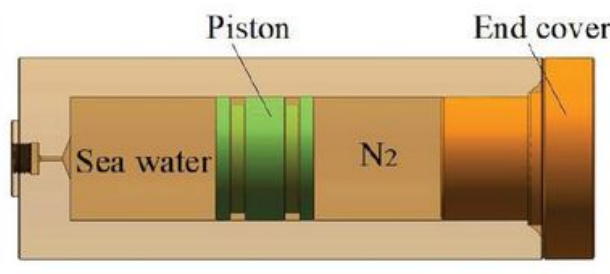

(b)

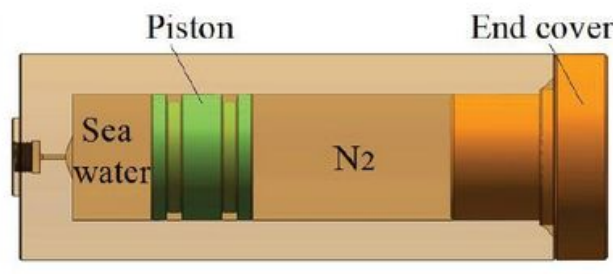

(c)

Figure 4

Motion process of pressure compensator piston.

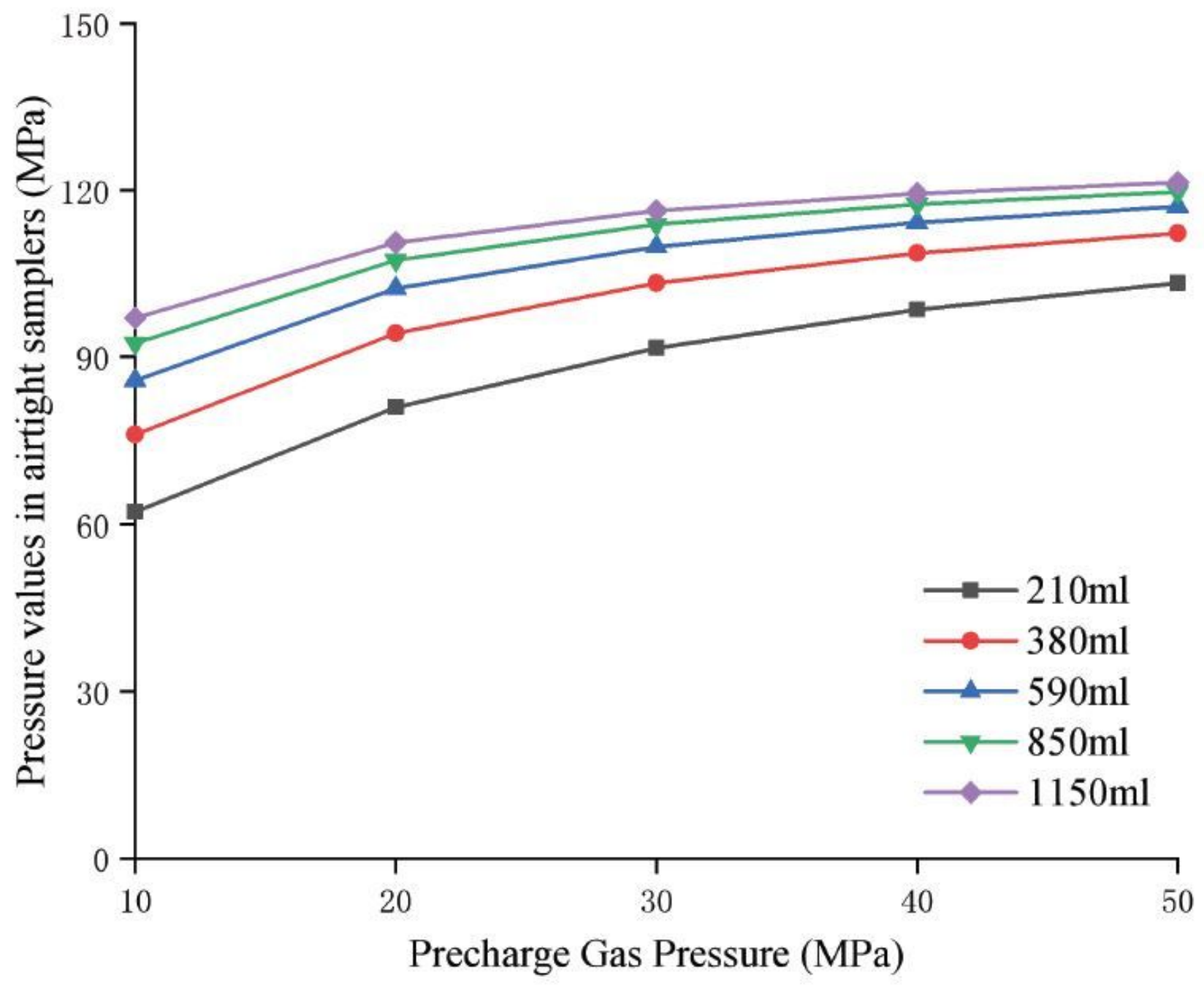

Figure 5

Relationship curve between precharge pressure of pressure compensator and pressure in GTSS. 


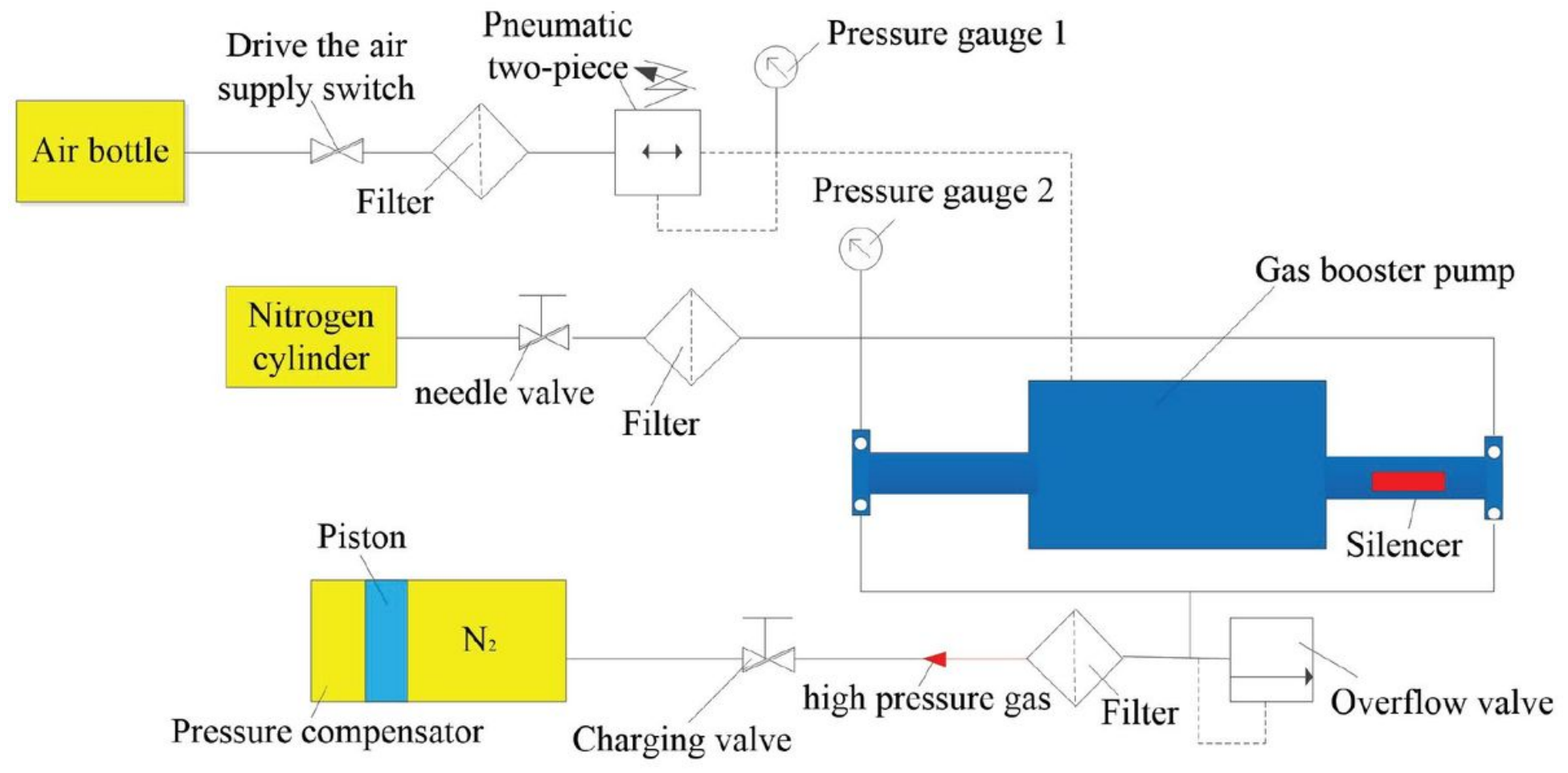

Figure 6

Schematic diagram of air tightness test of GTSS.

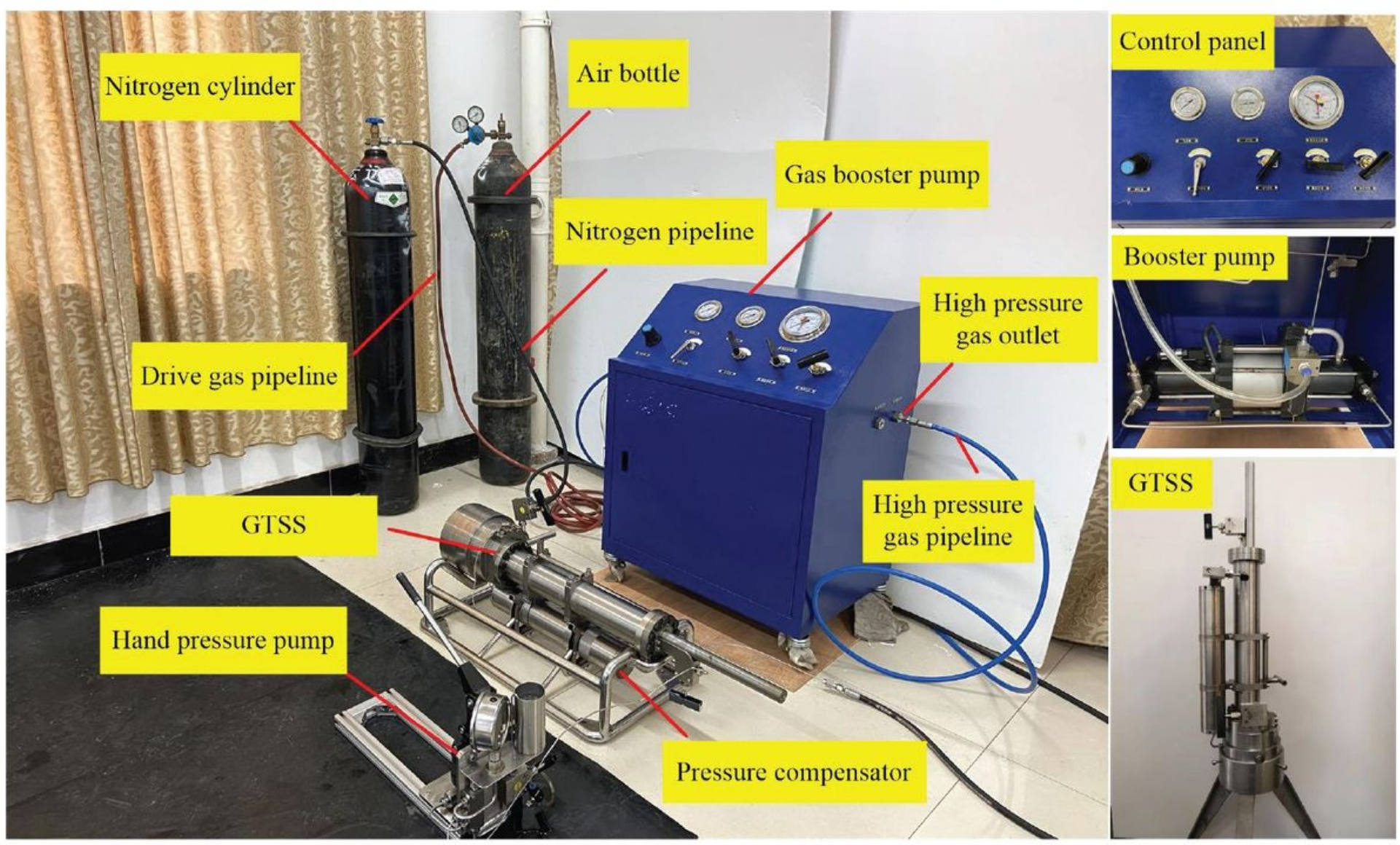

Figure 7 
Air tightness test of GTSS.

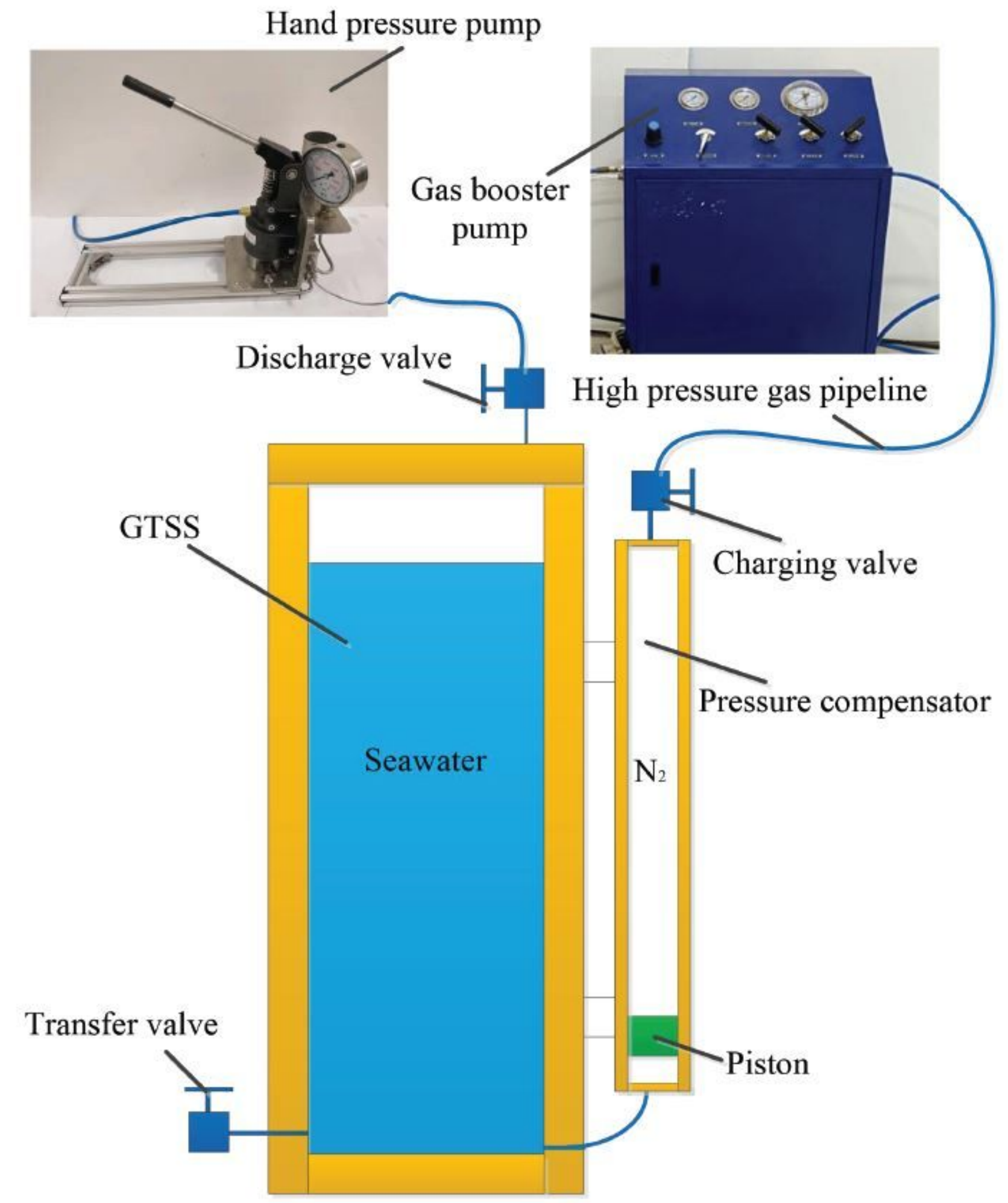

Figure 8

Schematic diagram of internal pressure test of GTSS. 


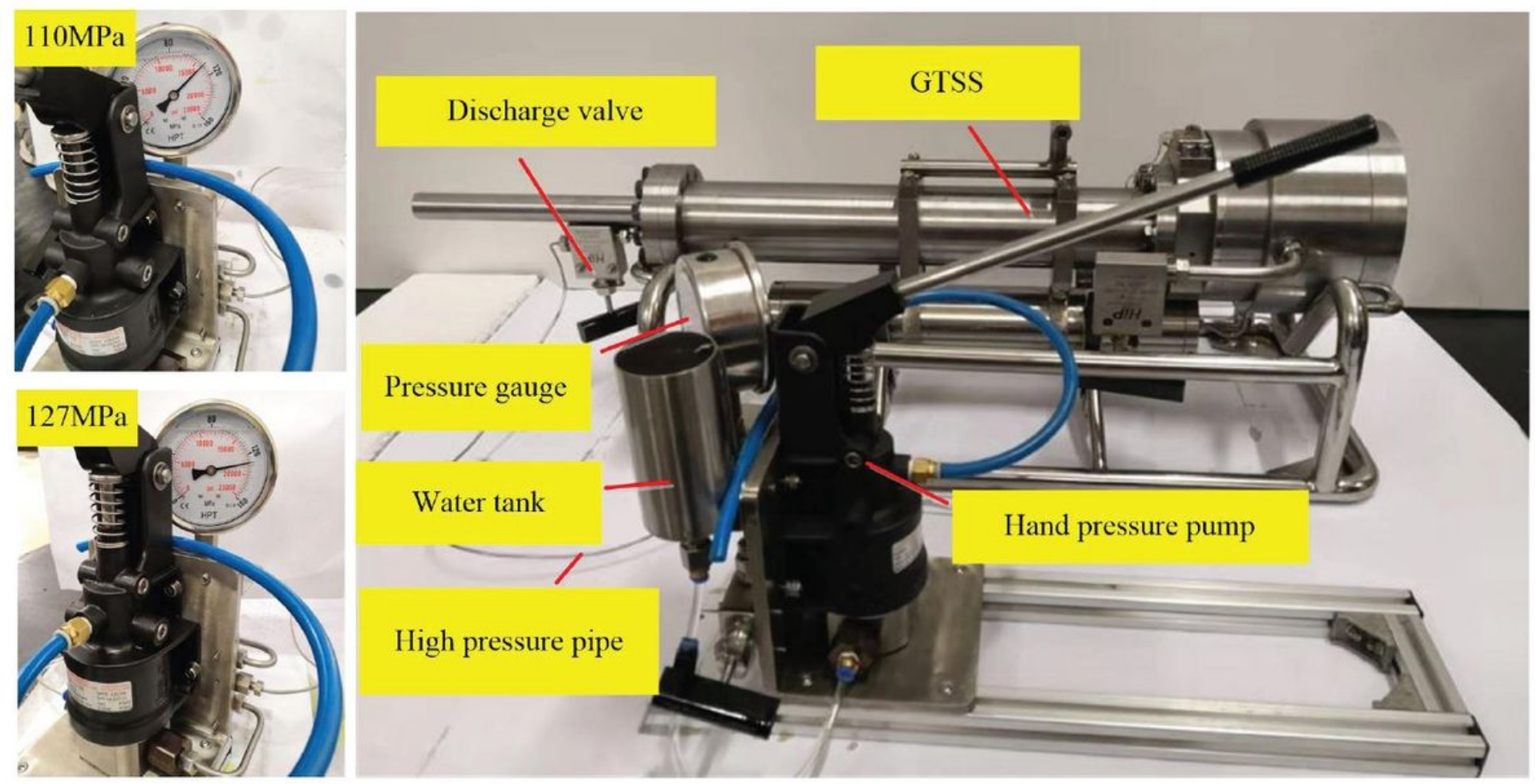

\section{Figure 9}

Internal pressure test of GTSS.

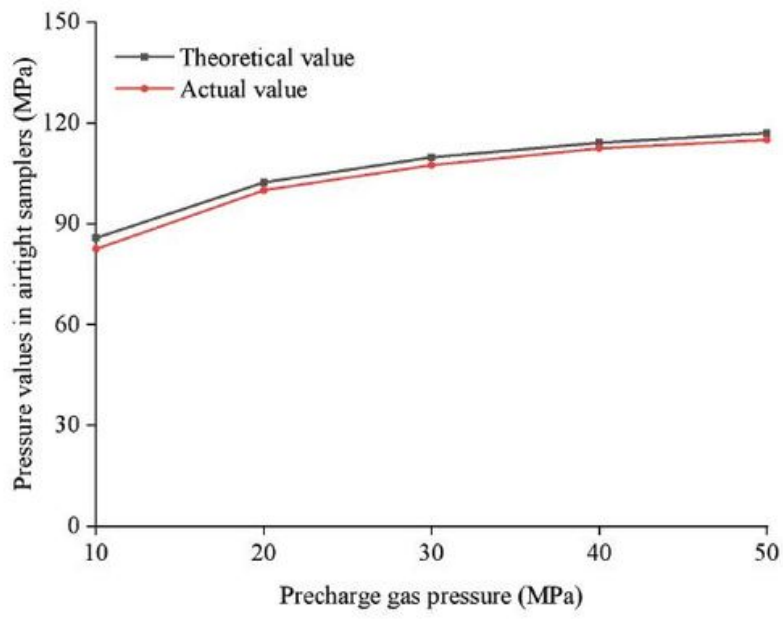

(a) $110 \mathrm{MPa}$

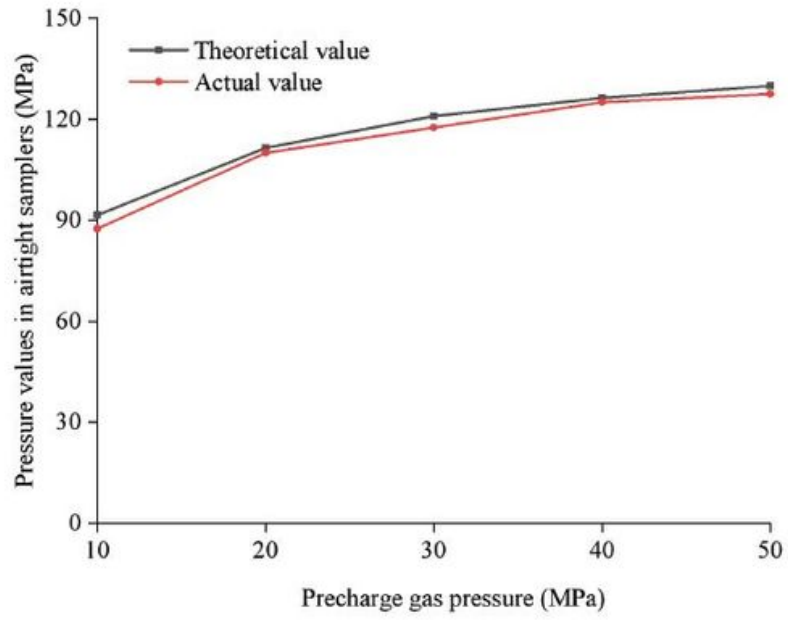

(b) $127 \mathrm{MPa}$

Figure 10

Actual and theoretical values of pressure in GTSS under different precharging pressures. 